\title{
REVIEW ARTICLE OPEN Extratropical forcing and tropical rainfall distribution: energetics framework and ocean Ekman advection
}

\author{
Sarah M. Kang ${ }^{1}$, Yechul Shin (1D) ${ }^{1}$ and Shang-Ping $\mathrm{Xie}^{2}$
}

Intense tropical rainfall occurs in a narrow belt near the equator, called the inter-tropical convergence zone (ITCZ). In the past decade, the atmospheric energy budget has been used to explain changes in the zonal-mean ITCZ position. The energetics framework provides a mechanism for extratropics-to-tropics teleconnections, which have been postulated from paleoclimate records. In atmosphere models coupled with a motionless slab ocean, the ITCZ shifts toward the warmed hemisphere in order for the Hadley circulation to transport energy toward the colder hemisphere. However, recent studies using fully coupled models show that tropical rainfall can be rather insensitive to extratropical forcing when ocean dynamics is included. Here, we explore the effect of meridional Ekman heat advection while neglecting the upwelling effect on the ITCZ response to prescribed extratropical thermal forcing. The tropical component of Ekman advection is a negative feedback that partially compensates the prescribed forcing, whereas the extratropical component is a positive feedback that amplifies the prescribed forcing. Overall, the tropical negative feedback dominates over the extratropical positive feedback. Thus, including Ekman advection reduces the need for atmospheric energy transport, dampening the ITCZ response. We propose to build a hierarchy of ocean models to systematically explore the full dynamical response of the coupled climate system.

npj Climate and Atmospheric Science (2018)1:20172 ; doi:10.1038/s41612-017-0004-6

\section{INTRODUCTION}

In the current climate of the Earth, 32\% of the globally integrated annual rainfall falls within $10^{\circ} \mathrm{S}-10^{\circ} \mathrm{N}$ (only $17 \%$ of the surface area) in a narrow band of heavy precipitation, called the inter-tropical convergence zone (ITCZ). The ITCZ is so sharp meridionally that a small shift in its position can cause dramatic local variations in rainfall. For example, Kanton Island near the edge of the ITCZ receives the annual rainfall of only $3 \mathrm{~mm} \mathrm{day}^{-1}$ in some years, while they can experience rainfall over $10 \mathrm{~mm}$ day $^{-1}$ in other years due to subtle shifts of the ITCZ. Also, the ITCZ migrates seasonally, with its zonal-mean position varying from $8.3^{\circ} \mathrm{S}$ in austral summer to $7.9^{\circ} \mathrm{N}$ in boreal summer. For example, precipitation at Port Morseby in Papua New Guinea varies from $3 \mathrm{~mm}$ day $^{-1}$ during dry months to $20 \mathrm{~mm} \mathrm{day}^{-1}$ during wet months. As hundreds of millions of the world population depend critically on tropical rains for water and food, it is of foremost importance to understand the mechanism that controls the ITCZ position.

Although tropical rainfall traditionally was thought to be controlled by local tropical mechanisms, ${ }^{1}$ paleoclimatic evidence has pointed at the possibility of an extratropical influence on tropical climate. The paleoclimate records from the tropical regions exhibit striking resemblance to the abrupt climate changes over Greenland associated with the Dansgaard-Oeschger events. $^{2,3}$ These paleoclimate data motivated the modeling studies of possible pathways for extratropics-to-tropics teleconnection by perturbing the extratropics in general circulation models. The extratropical perturbations include: increased ice cover in the high-latitude Northern Hemisphere $(\mathrm{NH}),{ }^{4}$ a sustained addition of freshwater in the North Atlantic, ${ }^{5,6}$ an expansion of dark forests in the northern extratropics, ${ }^{7-9}$ changes in radiative forcing agents, such as black carbon, sulfate, and volcanic aerosols, ${ }^{10}$ ozone depletion over Antarctica, ${ }^{11}$ and enhanced Southern Ocean heat uptake. ${ }^{12}$ In all cases, the ITCZ is shifted toward the differentially warmed hemisphere or away from the differentially cooled hemisphere. These modeling studies indicate that the extratropical perturbations can cause a meridional shift of the ITCZ, supporting the paleoclimate evidence. In the past decade, significant progress has been made in understanding how ITCZ shifts are forced from the extratropics based on the atmospheric energy budget. Here, we briefly review major advances made in this area of research, and highlight potential importance of ocean dynamic adjustments in modulating the extratropical impact on tropical rainfall.

\section{ITCZ AND ATMOSPHERIC ENERGY BUDGET}

Heavy rainfall in the ITCZ is caused by moisture convergence in the lower branch of the Hadley circulation (HC). The air masses that converge near the surface ascend and diverge in the upper troposphere. In general, the magnitude of dry static energy transport by the upper branch of the HC is larger than the magnitude of latent heat transport by the lower branch. Hence, atmospheric energy is transported in the same direction of the upper branch of the HC. Thus, the ITCZ closely corresponds to the latitude of maximum moisture convergence, and to the latitude where the atmospheric energy flux $F_{\mathrm{A}}$ vanishes, which is called the energy flux equator $\varphi_{\mathrm{e}}{ }^{13,14}$ (refer to Fig. 1). Suppose the northern extratropics are heated relative to the southern extratropics. The inter-hemispheric energy contrast can be connected to the ITCZ

\footnotetext{
${ }^{1}$ School of Urban and Environmental Engineering, Ulsan National Institute of Science and Technology, UNIST-gil 50, Ulsan 44919, Republic of Korea and ${ }^{2}$ Scripps Institution of Oceanography, University of California San Diego, 9500 Gilman Drive, MC 206, La Jolla, CA 92093, USA

Correspondence: Sarah M. Kang (skang.sarah@gmail.com)
}

Received: 9 December 2016 Revised: 27 April 2017 Accepted: 16 May 2017

Published online: 09 January 2018 


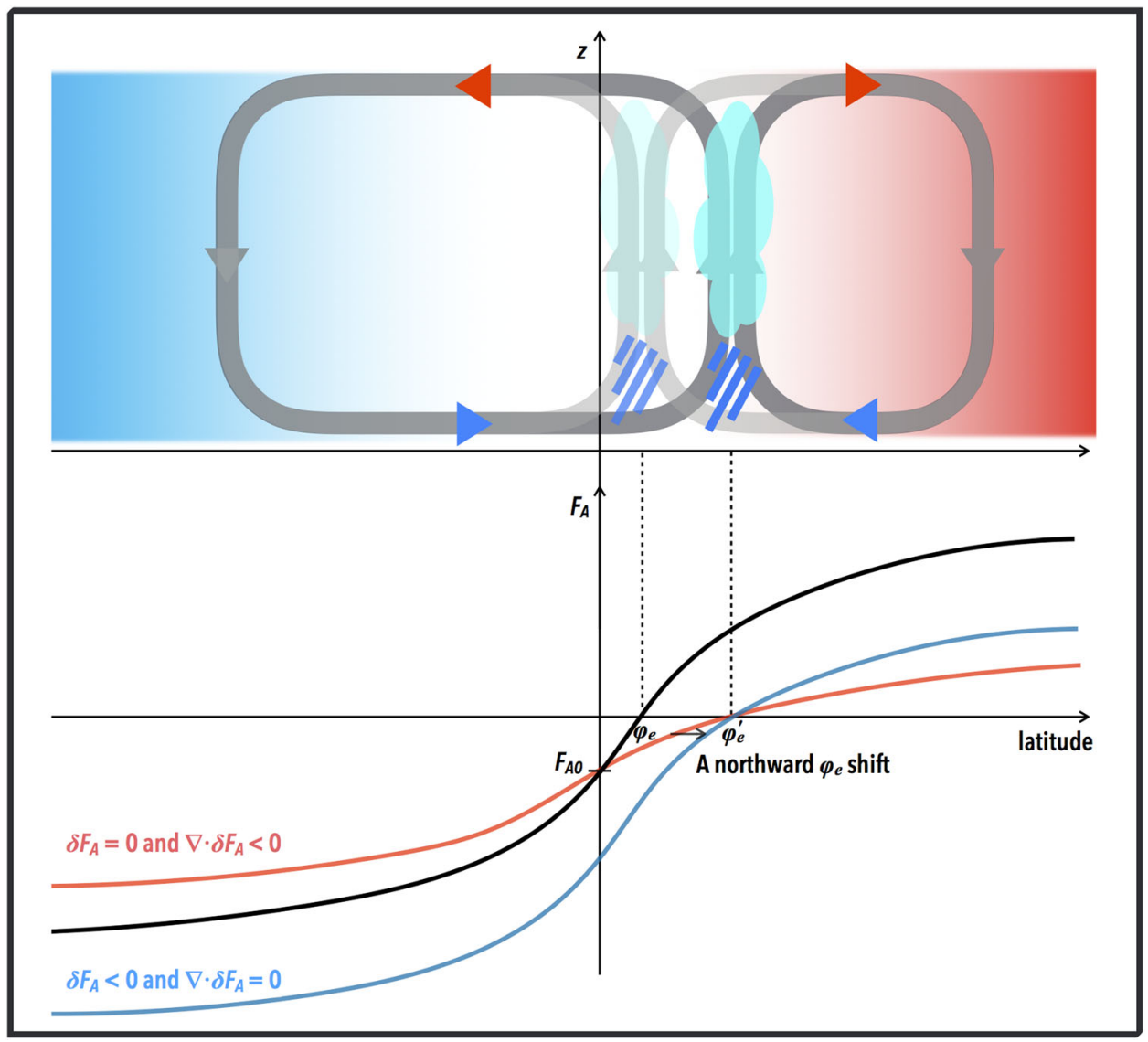

Fig. 1 Schematic that describes how inter-hemispheric extratropical thermal forcing is balanced by the adjustment of the Hadley circulation. Suppose the northern (southern) extratropics are warmed (cooled). The faded (dark) gray contours in the upper panel indicate the Hadley circulation in the reference (perturbed) state. The Hadley circulation transports moisture equatorward following its lower branch (blue arrow) and transports energy poleward following its upper branch (red arrow). In order to transport more energy to the $\mathrm{SH}$ (i.e., $\delta F_{\mathrm{A}}<0$ at $\varphi_{\mathrm{e}}$ ), the energy flux equator is shifted northward from $\varphi_{\mathrm{e}}$ to $\varphi_{\mathrm{e}}^{\prime}$. A northward $\varphi_{\mathrm{e}}$ shift can be induced either by an anomalously southward crossequatorial atmospheric energy transport (i.e., $\delta F_{\mathrm{A} 0}<0$ ) or by a reduction in the divergence of atmospheric energy transport (i.e., $\nabla \cdot \delta F_{\mathrm{A}}<0$ ) in the deep tropics. The former is indicated by blue and the latter is indicated by red in the lower panel

shift through the zonal-mean and time-mean vertically integrated atmospheric energy balance

$$
\nabla \cdot F_{\mathrm{A}}=R-O+S
$$

where $F_{\mathrm{A}}$ is the vertically integrated total meridional atmospheric energy transport (AET), $R$ is the net downward radiative fluxes at the top-of-atmosphere (TOA), $O$ is the ocean energy uptake due to transport and storage, and $S$ is the specified thermal forcing into the atmospheric column either from the TOA or from the surface. Let $\delta$ denote the response to $S$. The AET $F_{\mathrm{A}}$ can be expressed as $F_{\mathrm{A}}=-V \Delta m$, where $V$ is the $\mathrm{HC}$ mass transport by its lower branch $(\delta V>0$ at the equator for a northward displaced ITCZ) and $\Delta m$ is the total gross moist stability (TGMS) that measures the efficiency at which the HC transports energy. The TGMS is usually positive, indicative of a larger energy transport by the upper branch than the lower branch of the $\mathrm{HC} .^{15,16}$

An energetics framework that relates the ITCZ response to the hemispherically differential heating was developed using experiments with atmospheric models coupled to a motionless slab ocean, in which energy can be transported within the atmosphere only (i.e., there is no change in 0 ).$^{13,15,17}$ Consider a simple case where cloud radiative effects are inhibited. The effect of extratropical forcing $(S>0$ in $\mathrm{NH}$ and $S<0$ in $\mathrm{SH}$ ) reaches the subtropical edge of the $\mathrm{HC}$ via atmospheric eddy fluxes. ${ }^{15}$ The resultant meridional temperature gradients in the tropical upper troposphere cannot be sustained due to the smallness of the Coriolis parameter. ${ }^{18}$ In order to flatten temperature gradients, the
$\mathrm{HC}$ responds by transporting excessive energy from the $\mathrm{NH}$ to the $\mathrm{SH}$ with a deficit of energy. In other words, the energy has to be transported southward across the energy flux equator in the reference state, which requires a northward shift of the energy flux equator. There are largely two ways to induce a northward shift of the energy flux equator, as demonstrated in Fig. 1. One is by lowering the $y$-intercept while keeping the overall meridional profile the same (i.e., $\delta F_{\mathrm{A} 0}<0$, with the subscript 0 denoting the equator, and $\nabla \cdot \delta F_{\mathrm{A}}=0$ ). That is, an anomalously southward cross-equatorial $A E T$ leads to a northward shift of the energy flux equator. ${ }^{13,19}$ The other is by reducing the meridional slope of AET in the equatorial region with an unchanged $y$-intercept (i.e., $\nabla$. $\delta F_{A}<0$ and $\left.\delta F_{A} 0=0\right)$. That is, a reduction in the divergence of $A E T$ in the tropics, equivalent to the net energy input into the atmospheric column based on Eq. 1, leads to a northward shift of the energy flux equator. ${ }^{20,21}$ The former case is depicted in blue in Fig. 1 and the latter in red. The effect of extratropical forcing is primarily balanced by a cross-equatorial AET, while the effect of tropical forcing, such as El Niño primarily modulates the net energy input to the equatorial atmosphere. ${ }^{20}$

The response of the energy transport can be directly related to the response of mass transport in the lower troposphere, that is, $\delta F_{\mathrm{A}}=-\Delta m \delta V$, assuming a fixed $\Delta m$. Hence, the anomalous southward energy transport, which is accompanied by the northward shift of the energy flux equator, causes an anomalous northward moisture transport in the lower troposphere, corresponding to a northward ITCZ shift (Fig. 1). This elucidates how 
hemispherically asymmetric heating in the extratropics can affect tropical rainfall. Extratropical forcing tends to be amplified when cloud-radiative effects are included, whereas tropical forcing tends to be damped. ${ }^{13,15,22}$ Hence, remote extratropical forcing can actually be more effective at shifting the ITCZ than local tropical forcing. ${ }^{22}$ In summary, a thermal contrast between the hemispheres, introduced from the tropics or from the extratropics, can force an ITCZ shift in order to balance the atmospheric energy budget.

The energetics framework facilitates the development of a new theory for why the climatological zonal-mean ITCZ position is north of the equator, emphasizing the importance of the Atlantic meridional overturning circulation (AMOC) and its northward transport of energy across the equator. ${ }^{23-25}$ The effect of the AMOC is zonally homogenized by winds in the extratropics, thereby placing the ITCZ in the NH not only in the Atlantic but also in the Pacific. ${ }^{26}$ Traditionally, the ITCZ position was thought to be controlled by local mechanisms, such as the shape of coast lines ${ }^{1,27,28}$ and Andes topography. ${ }^{29}$ These local processes may be important for the zonal variations of the $I T C Z^{26,30}$ as the global energetics framework applies to the zonal mean. The northward heat transport by the AMOC also explains why the $\mathrm{NH}$ is warmer than the SH on average. ${ }^{31}$ Seasonal variations in ITCZ location can also be thought of as the result of an anomalous $\mathrm{HC}$ that must transport energy toward the differentially cooled hemisphere. ${ }^{14,32}$ The energetics framework has been successfully adopted to explain the ITCZ shifts in response to a doubling of $\mathrm{CO}_{2}$ in comprehensive models ${ }^{33}$ and the response to aerosols in the 20th century. ${ }^{34}$ Moreover, the energetics framework has been applied to diagnose the double-ITCZ problem, which is a long-standing climate model bias. ${ }^{35}$ Cloud biases over the Southern Ocean, responsible for excessive warming over the $\mathrm{SH}^{36}$ have been suggested to be one of the causes of the double-ITCZ.

\section{LIMITATIONS AND WAYS FORWARD}

The energetics framework assumes that the TGMS, $\Delta m$ is constant. If $\Delta m$ can vary, $\delta F_{\mathrm{A}}$ is no longer directly related to $\delta V$ and cannot account for the ITCZ shift. For example, consider the limiting case with $\delta F_{\mathrm{A}}=0$ where the present energetics framework predicts no ITCZ shift. If changes in $\Delta m$ were large, there would be substantial changes in the mass transport, despite $\delta F_{A}=0$, resulting in the ITCZ shift. One can consider the other limiting case where $\delta F_{\mathrm{A}} \neq 0$ is accompanied by no ITCZ shift but results entirely from changes in $\Delta m$ (i.e., $\delta F_{\mathrm{A}}=V \delta \Delta m$ ). As $\delta \Delta m$ becomes more dominant over $\delta V$ in determining $\delta F_{A}$, the energetics framework starts to fail in predicting the ITCZ response. The relative importance between $\delta \mathrm{V}$ and $\delta \Delta m$ may depend on the type of forcing. An interhemispheric thermal contrast is expected to provoke a significant $\mathrm{HC}$ shift with relatively little changes in $\Delta m$. Then, the energy flux equator can be used to infer the ITCZ shift. In contrast, a nearly uniform radiative forcing induces a rather subtle $\mathrm{HC}$ shift and changes in $\Delta m$ cannot be ignored. ${ }^{37-40}$ In this situation, the energy flux equator is no longer a good proxy for the ITCZ. ${ }^{16}$ Therefore, one must account for changes in the TGMS for a complete theory.

For the energetics framework to have a full predictive power, it must also predict how radiative feedbacks would rectify the external forcing. For example, the zonally asymmetric thermal forcing with zero zonal-mean component is expected not to cause any ITCZ shift assuming radiative feedbacks are linear. However, nonlinear cloud-radiative feedbacks can cause a significant shift in the zonal-mean ITCZ. ${ }^{41,42}$ Furthermore, a given inter-hemispheric forcing can cause an ITCZ shift that varies in magnitude by more than $100 \%$ when a convection scheme parameter is tuned in a model in a way that alters the strength of cloud radiative effect. ${ }^{13,43}$ Model spread in cloud response is a dominant source for model spread in the ITCZ shift in response to inter-hemispheric forcing. ${ }^{44}$ Hence, without properly understanding cloud radiative effects, the framework cannot make a useful quantitative prediction. Since tropical clouds are strongly tied to the circulation, ${ }^{45}$ one may seek to formulate a closed theory by constructing an empirical relationship between cloud radiative effect and circulation based on observations.

The energetics framework is based on the zonal-mean atmospheric energy budget, hence, has limited relevance to regional changes. The zonal-mean ITCZ lumps together rich regional structures, such as monsoons, one of the most prominent local features of tropical circulation. The zonal-mean ITCZ shift may not convey the proper information on the changes of regional rainfall pattern. For example, the zonal-mean ITCZ position shifts only by about $1^{\circ}$ in latitude between El Niño and La Niña composites, while the east-west shifts are $22^{\circ}$ in longitude. ${ }^{46}$ Also, during the early Holocene, compared to today, the zonal-mean ITCZ shift is estimated to be less than $1^{\circ}$ latitude, while paleoclimate records infer that the regional ITCZ shifts reach up to $5^{\circ}$ latitude. $^{47}$ Although some aspects of regional features, such as the abrupt onset of monsoon are captured by the zonal-mean dynamics, ${ }^{48}$ planetary-scale waves are important. For example, the summer monsoons extend farther poleward in the eastern than western side of a major continent like the Afro-Eurasian. ${ }^{49-51}$ Thus, expanding the zonal-mean energetics framework to two horizontal dimensions is required for predictions of regional rainfall changes in the tropics, say by accounting for the zonal component of divergent AET. ${ }^{46,52}$

The application of the energetics framework is further complicated by ocean dynamical feedback. When the ocean circulation is allowed to respond (i.e., $O$ is no longer fixed in Eq. 1), the partitioning of energy transport between the atmosphere and ocean will determine the magnitude of the ITCZ response. Recently, fully coupled models with a dynamical ocean are employed to examine the ITCZ response to high-latitude energy perturbation. ${ }^{53-57}$ In response to modified Southern Ocean albedo, the changes in cross-equatorial energy transport are dominated by ocean adjustments, and the ITCZ response is muted with a persistent double-ITCZ problem ${ }^{53,54}$ in some models (CESMCAM $5^{58}$ and HadGEM2-ES ${ }^{59}$ ). Similarly, when the model $\left(\mathrm{CCSM} 4^{60}\right.$ ) is forced by the projected Arctic sea ice loss, the climate response exhibits a high degree of hemispheric symmetry with little ITCZ shift, as the energy transport is mostly accomplished by the ocean in the equatorial region. ${ }^{61,62}$ In contrast, in a different model (GFDL AM4 coupled to FLOR $^{63}$ ), the atmosphere and ocean nearly equally share the load of compensating the variations in the solar flux over the Southern Ocean, and a small but clear meridional ITCZ shift is identified. ${ }^{55}$ In another GFDL family of climate models (GFDL CM2Mc ${ }^{64}$ ), the changes in cross-equatorial energy transport equally occurred in the atmosphere and ocean in response to $\mathrm{SH}$ high-latitude radiative changes associated with Southern Ocean convective variability. ${ }^{57}$ In response to a reduction of solar flux over the Southern Ocean, the UCLA CGCM produces a significant ITCZ shift whereas a much weaker ITCZ response is obtained in the NorESM model. ${ }^{56}$ These studies that employ fully coupled models suggest a large inter-model spread in the degree by which the ocean circulation modulates the tropical response to extratropical forcing. In general, extratropical energy perturbations are not as effective at forcing the ITCZ shift as predicted by the energetics framework with a slab ocean. This is expected due to an intimate coupling between the subtropical ocean cell and the $\mathrm{HC}$ through the trade winds. ${ }^{65}$ As the ocean transports energy in the same direction as the $\mathrm{HC}$, the amount of energy needed to be transported by the atmosphere will decrease, leading to a reduction in the tropical rainfall response. The cause of such a large inter-model spread in ocean dynamical compensation remains to be explored. 

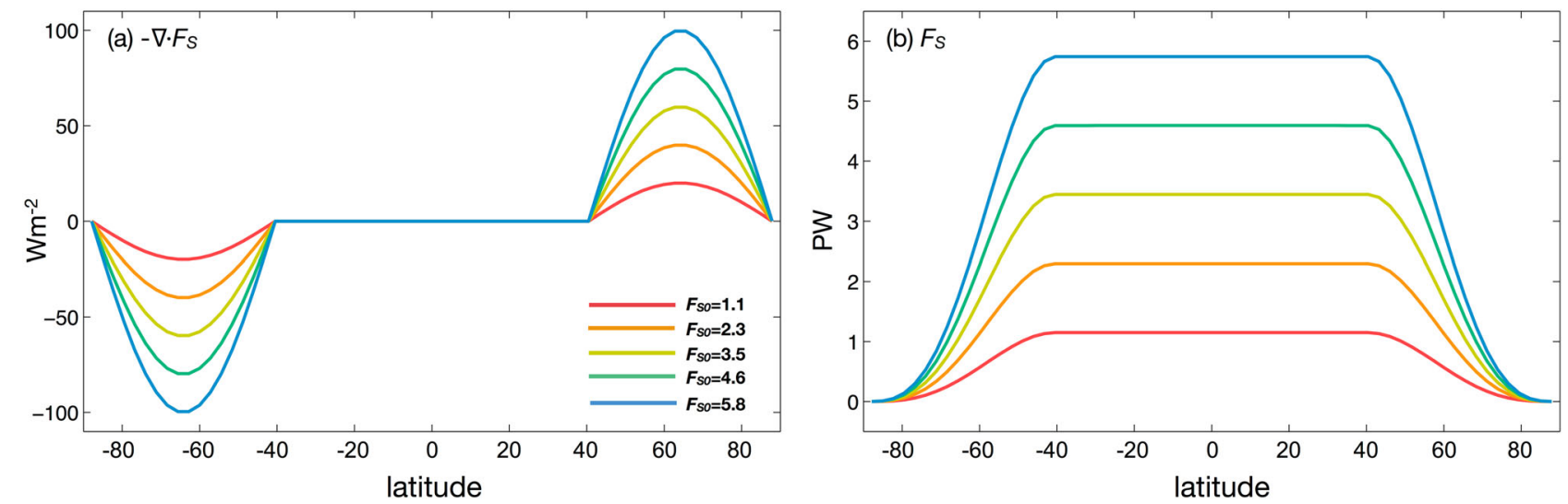

Fig. 2 The form of prescribed thermal forcing in the slab ocean. a The convergence of prescribed ocean energy transport, $S\left(\mathrm{~W} \mathrm{~m}^{-2}\right)$. The maximum amplitude varies from 20 to $100 \mathrm{~W} \mathrm{~m}^{-2}$. b Latitudinal integral of zonally integrated (a) from one pole to the other, such that $S=-\nabla \cdot F_{\mathrm{S}}$. The cross-equatorial transport $F_{\mathrm{SO}}$ varies from 1.1 to $5.8 \mathrm{pW}$

\section{OCEAN DYNAMICS AND THE ITCZ}

This section considers ocean dynamical feedback that affects the partitioning of energy transport between the atmosphere and ocean. We attempt to provide a possible explanation for a range of sensitivity of tropical rainfall to extratropical forcing in coupled models with a fully dynamic ocean. In fully coupled models, it is difficult to disentangle the effect of different components of the large-scale ocean circulation including the thermohaline and wind-driven circulation, so for better understanding one might wish to reduce the complexity of the climate system. ${ }^{66}$ Therefore, we propose to build a hierarchy of climate models in which a simplified atmospheric model is coupled to ocean models of different levels of complexity. The atmospheric model we employ has no cloud radiative feedbacks, a key source of uncertainty, to focus on more fundamental interactions between latent heating and circulation. ${ }^{67,68}$ The ocean model is also intended to be as simple as possible yet contains dynamics of meridional energy transport. In the tropics, energy is transported poleward primarily by the wind-driven circulation, which consists of poleward Ekman flow at the surface and the equatorward return flow in the thermocline that upwells in the equatorial region. ${ }^{69-72}$ Here, we implement meridional Ekman advection into the aquaplanet slab ocean model, while neglecting the upwelling effect in the deep tropics and the subsiding effect in the subtropics. ${ }^{73}$ That is, we only incorporate the effect of meridional heat advection at the surface by the Ekman flow, without the need to include the vertical stratification of the ocean. The shallow overturning cell that sinks in the subtropics with the return flow in the thermocline will be considered in a subsequent study by adopting a two-layer ocean model. ${ }^{74}$ Systematically adding the complexity to the ocean model is expected to help develop fundamental understanding of how the ocean circulation modulates the extratropics-to-tropics teleconnection.

The meridional Ekman flow $\left(v_{\mathrm{Ek}}\right)$ is induced by a zonal wind stress $\left(\tau_{x}\right)$ :

$v_{\mathrm{Ek}}=-\frac{f}{f^{2}+\varepsilon^{2}} \frac{\tau_{x}}{\rho h}$ where $f$ is the Coriolis parameter, $\varepsilon$ is the mechanical damping rate $\left(5.7 \times 10^{-6} \mathrm{~s}^{-1}\right), \rho$ is the density of water $\left(1 \times 10^{3} \mathrm{~kg} \mathrm{~m}^{-3}\right)$, and $h$ is the mixed layer depth $(50 \mathrm{~m})$ (see section "Methods" for more details). To simulate the effect of meridional Ekman heat advection, we add the term $-\rho C_{\mathrm{p}} h v_{\mathrm{Ek}} \frac{\partial T_{\mathrm{S}}}{a \partial \varphi}$ (where $\frac{\partial T_{\mathrm{S}}}{\partial \varphi}$ indicates meridional surface temperature gradients with the radius of the earth $a$ and a specific heat at constant pressure $C_{p}$ ) to the surface temperature tendency equation. ${ }^{75,76}$ The meridional energy transports by the Ekman flow $F_{\text {Ek }}$ are calculated across each latitude band $(\varphi)$ by integrating the Ekman heating term from one pole to the other: $F_{\mathrm{Ek}}(\varphi)=\int_{-\pi / 2}^{\varphi} \int_{0}^{2 \pi}\left(-\rho C_{\mathrm{p}} h v_{\mathrm{Ek}} \frac{\partial T_{\mathrm{s}}}{\partial \partial \varphi}\right) a^{2} \cos \varphi d \lambda d \varphi$, where $\lambda$ is longitude. It is noted that our aquaplanet model may produce an upper bound of the zonally integrated Ekman mass transport and associated energy transport due to the absence of ocean basins. In regions with surface easterlies, the Ekman flow is directed poleward, leading to warm advection. Conversely, in regions with surface westerlies, the Ekman flow is directed equatorward, leading to cold advection. Hence, when Ekman advection is implemented, the equatorial peaks of the mean surface temperature and rainfall in the symmetric reference run are slightly enhanced, whereas the surface temperature in the mid-latitudes is slightly cooled (Fig. 3a and c). With the upwelling effect, which is to be considered in the subsequent study, the equatorial peak is expected to be damped, broadening the warm pool.

In both models with and without Ekman advection, the reference climate is simulated with no surface flux adjustments $(S=0)$. We then perturb the reference climate with an antisymmetric forcing $S$ that extracts heat at the surface poleward of $40^{\circ} S$ and injects it poleward of $40^{\circ} \mathrm{N}$ (Fig. 2a). Because of the zero global mean, the prescribed antisymmetric surface thermal forcing $S$ can be described in terms of an implied northward ocean energy transport $F_{S}$, with $S=-\nabla \cdot F_{S}$ (Fig. 2b). The maximum amplitude of $S$ is varied such that its corresponding cross-equatorial flux, denoted as $F_{\mathrm{SO}}$, ranges from 1.1 to $5.8 \mathrm{pW}$. The range of forcing would correspond to $0.28-1.45 \mathrm{pW}$ in a comprehensive model where cloud radiative effects amplify the prescribed forcing by a factor of four. ${ }^{15}$

With the inclusion of Ekman flow that is dynamically coupled to surface wind stress, the ocean energy uptake $O$ in Eq. 1 can be written in terms of a meridional Ekman heat transport $F_{\mathrm{Ek}}$, with $O$ $=\nabla \cdot F_{\mathrm{Ek}}$. The anomalous atmospheric energy balance can be represented as

$\nabla \cdot \delta F_{\mathrm{A}}+\nabla \cdot \delta F_{\mathrm{R}}+\nabla \cdot \delta F_{\mathrm{Ek}}=-\nabla \cdot F_{\mathrm{S}}$

where $\delta$ denotes the response to extratropical forcing $S$. For convenience, $\delta R$, with the global mean removed, is expressed as the convergence of a flux such that $\delta R=-\nabla \cdot \delta F_{\mathrm{R}}$. The AET response $\left(\delta F_{\mathrm{A}}\right)$ to the prescribed forcing $F_{\mathrm{S}}$ is modulated by the strengths of radiative $\left(\delta F_{\mathrm{R}}\right)$ and Ekman $\left(\delta F_{\mathrm{Ek}}\right)$ feedbacks.

We compare the tropical responses to the prescribed northward flux in the model with and without Ekman advection to examine the role of meridional Ekman advection on modulating the ITCZ response to the extratropical thermal forcing. In response to the prescribed northward flux $F_{\mathrm{S}}$, the tropical precipitation is clearly shifted to the north in the absence of any ocean dynamics (dashed in Fig. 3d), whereas a much weaker or even reversed response of tropical precipitation is obtained with the Ekman advection (solid in Fig. 3d), consistent with fully coupled model results. 

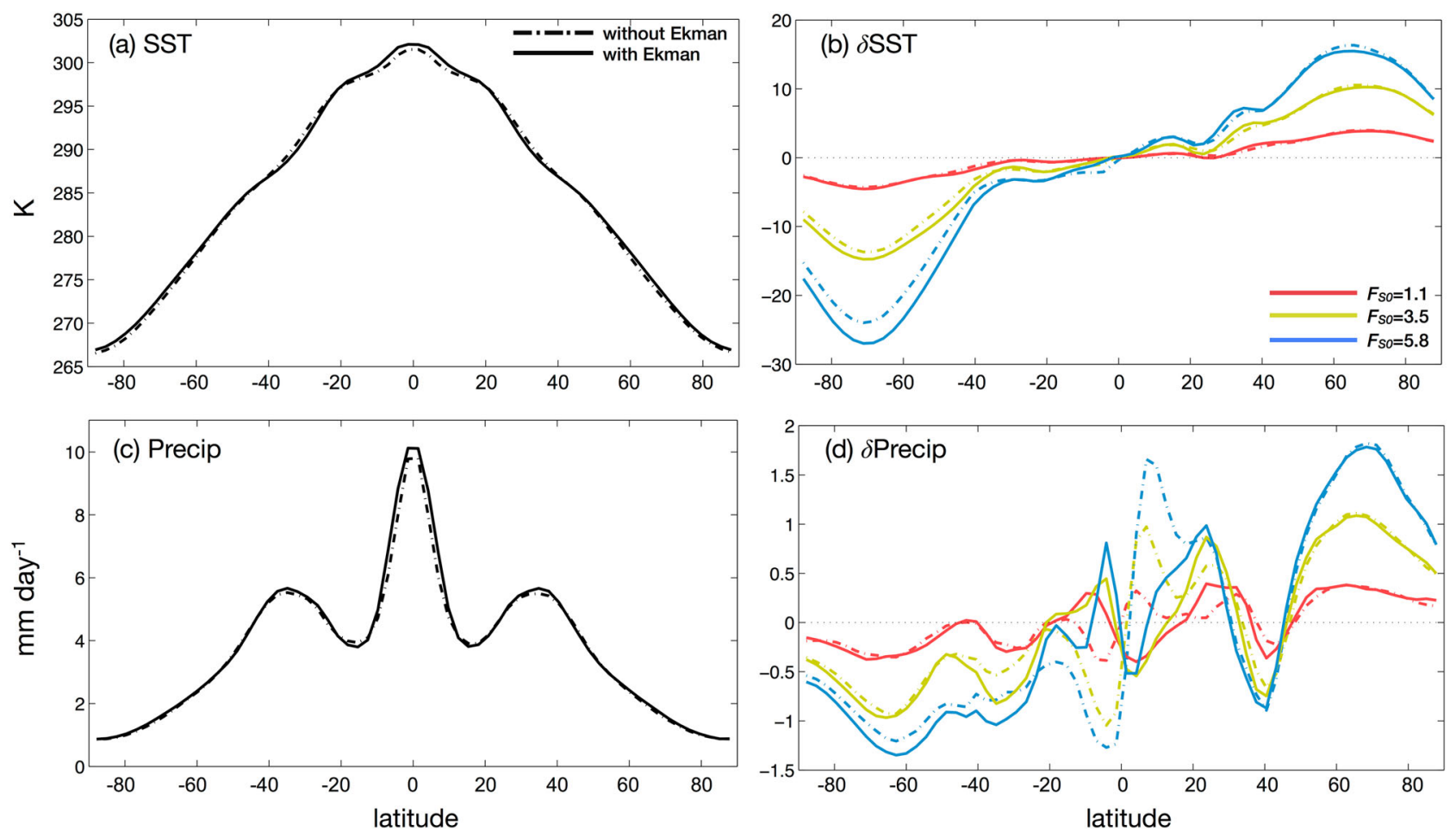

Fig. 3 The reference climate state and the response to extratropical thermal forcing. The zonal-mean a sea surface temperature (K) and $c$ precipitation $\left(\mathrm{mm} \mathrm{day}^{-1}\right)$ in the reference state. $\mathbf{b}, \mathbf{d}$ The responses of $\mathbf{a}, \mathbf{c}$ to the extratropical thermal forcing. Dash-dot (solid) is for the model without (with) the Ekman advection

(a) without Ekman

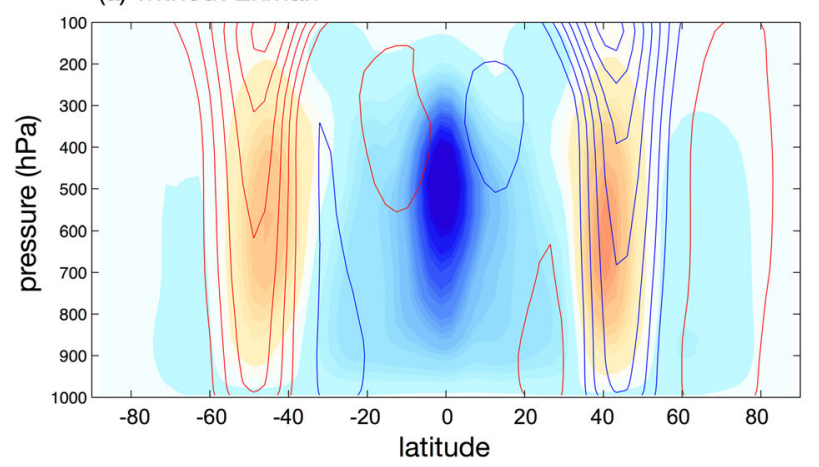

(b) with Ekman

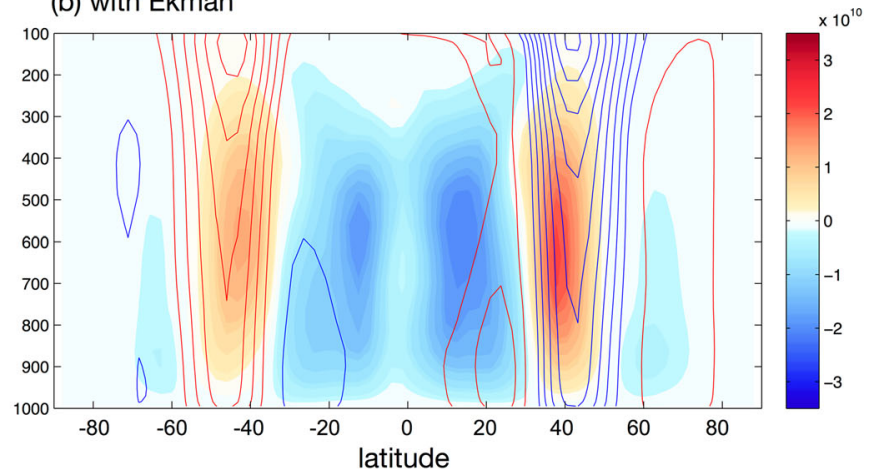

Fig. 4 The response of zonal-mean climate. Stream function of anomalous meridional overturning circulation when $F_{\mathrm{SO}}=1.1 \mathrm{PW}(\mathrm{shading}$, interval $\left.2 \times 10^{9} \mathrm{~kg} \mathrm{~s}^{-1}\right)$. Blue denotes the counter-clockwise circulation and red denotes the clockwise circulation. Anomalous zonal-mean zonal wind (contour at interval $1 \mathrm{~m} \mathrm{~s}^{-1}$, positive in red and negative in blue). In the model (a) without and (b) with the Ekman advection

First, consider cases without Ekman advection (i.e., $F_{\mathrm{Ek}}=0$ ). As the southern extratropics are cooled, the mid-latitude jet in the $\mathrm{SH}$ strengthens and shifts poleward due to enhanced meridional temperature gradients ${ }^{77}$ (Fig. 4a). The $\mathrm{NH}$ presents an opposite response, albeit weaker in magnitude as smaller SST changes are induced in the warmed $\mathrm{NH}$ than in the cooled SH (Fig. 3b). This is because the turbulent fluxes require larger SST changes under a colder and drier mean state to balance the prescribed surface heating. ${ }^{22,42}$ The contrast may be enhanced in comprehensive models since nonlinear cloud radiative effect changes amplify the forcing in the cooling region. ${ }^{41}$ The strengthened (weakened) eddy fluxes in the $\mathrm{SH}(\mathrm{NH})$ extract more (less) energy out of the tropics. $^{78}$ As the southern (northern) tropics become colder (warmer), the southern (northern) $\mathrm{HC}$ becomes stronger (weaker), resulting in an anomalous counter-clockwise $\mathrm{HC}^{32,79}$ (Fig. 4a). This accompanies a northward displaced ITCZ and southward crossequatorial AET (red in Fig. 5a). Regardless of the amplitude of $F_{\mathrm{SO}}$, the AET response $\left(\delta F_{\mathrm{A}}\right)$ in the tropics compensates about $20-25 \%$ of the prescribed forcing $F_{\mathrm{SO}}$ while the remainder is compensated by local radiative fluxes $\left(\delta F_{\mathrm{R}}\right)$ (Fig. $5 \mathrm{a}$ and b). The results are consistent with previous studies. ${ }^{15}$ As a result, there is a northward shift of the energy flux equator as well as the tropical rainfall, which increases in magnitude as the prescribed forcing is strengthened (dash-dot in Fig. 6).

Next, consider cases with Ekman advection, i.e., $F_{\mathrm{Ek}} \neq 0$ (refer to Fig. 7). In the tropics, accompanied by a strengthening (weakening) of the southern (northern) $\mathrm{HC}$, the surface easterlies in the $\mathrm{SH}$ $(\mathrm{NH})$ become stronger (weaker). The asymmetric zonal surface wind anomalies in the two hemispheres induce an anomalously southward Ekman flow in the tropics that brings about warm (cold) advection in the southern (northern) tropics. This opposes the effect of prescribed extratropical forcing, leading to a reduction in the surface temperature response in the deep tropics as compared to the model without Ekman advection (Fig. 3b). On 

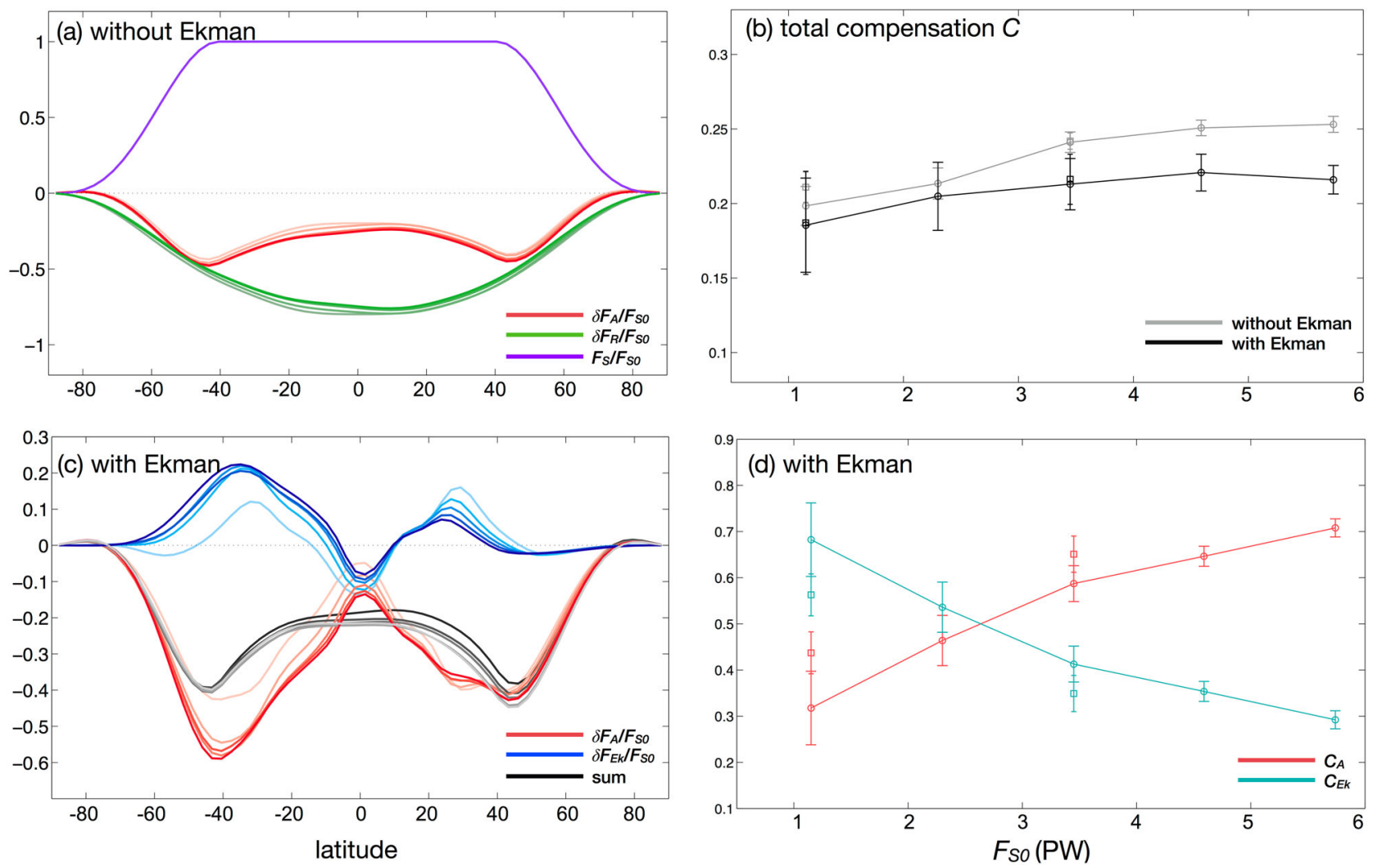

Fig. 5 Compensation of extratropical thermal forcing. a The imposed extratropical surface heating $F_{\mathrm{S}}$ (purple), the response of atmospheric energy transport $\delta F_{\mathrm{A}}(\mathrm{red})$, the response of radiative fluxes $\delta F_{\mathrm{R}}$ (green), in the model without the Ekman advection. All normalized by $F_{\mathrm{sO}}$. $\mathbf{b}$ The total compensation $C \equiv\left(\delta F_{\mathrm{A}}+\delta F_{\mathrm{Ek}}\right) / F_{\mathrm{SO}}$ averaged between $5^{\circ} \mathrm{S}$ and $5^{\circ} \mathrm{N}$ as a function of $F_{\mathrm{SO}}$. Dash-dot (solid) is for the model without (with) the Ekman advection. $\mathbf{c}$ The response of atmospheric energy transport $\delta F_{\mathrm{A}}$ (red), the response of meridional Ekman heat transport $\delta F_{\mathrm{Ek}}$ (blue), and their sum (black), in the model with the Ekman advection. All normalized by $F_{\mathrm{so}}$. $\mathbf{d}$ The atmospheric compensation $C_{\mathrm{A}} \equiv \delta F_{\mathrm{A}} /\left(\delta F_{\mathrm{A}}+\delta F_{\mathrm{Ek}}\right)$ in red and the Ekman compensation $C_{\mathrm{Ek}} \equiv \delta F_{\mathrm{Ek}} /\left(\delta F_{\mathrm{A}}+\delta F_{\mathrm{Ek}}\right)$ in blue, in the model with the Ekman advection. In (a, c), the line colors are faded out as the amplitude of $F_{\mathrm{SO}}$ decreases. In (b, d), the squares indicate the results from the model with a mixed layer depth of $25 \mathrm{~m}$, and bars indicate the $95 \%$ confidence interval

the other hand, in the extratropics, the surface westerlies are strengthened (weakened) in the $\mathrm{SH}(\mathrm{NH})$ associated with a poleward (equatorward) jet shift. An anomalously northward Ekman flow is induced in both hemispheres that brings about cold (warm) advection in the southern (northern) extratropics. This amplifies the effect of the prescribed extratropical forcing, leading to an increase in the surface temperature response in the extratropics (Fig. 3b).

Figure 5c compares the latitudinal profiles of $\delta F_{\mathrm{A}}$ and $\delta F_{\mathrm{Ek}}$ normalized by $F_{\mathrm{So}}$. It clearly shows that the effects of meridional Ekman heat advection in the tropics and the extratropics counteract each other. The tropical component acts as a negative feedback that partially compensates for the prescribed forcing, whereas the extratropical component acts as a positive feedback that amplifies the prescribed forcing. The extratropical component is larger in the $\mathrm{SH}$ than in the $\mathrm{NH}$ due to greater jet shifts associated with larger SST changes. Overall, the negative feedback from the tropical component dominates over the positive feedback from the extratropical component, so that the need for the cross-equatorial AET is reduced with Ekman advection. One can define the degree of compensation of the prescribed forcing by the atmospheric and Ekman transport as the total compensation $C$ (i.e., $\left.C \equiv\left(\delta F_{\mathrm{A}}+\delta F_{\mathrm{Ek}}\right) / F_{\mathrm{SO}}\right)$ averaged between $5^{\circ} \mathrm{S}$ and $5^{\circ} \mathrm{N}$. The total compensation becomes weaker by less than $10 \%$ with the inclusion of Ekman advection, possibly due to the extratropical positive feedback (contrast solid and dash-dot in Fig. 5b). This is in contrast to other fully coupled models where the total compensation is slightly enhanced compared with that in the coupled atmosphere-slab ocean models. ${ }^{61,62,65}$ It is yet to be examined what determines the total compensation in the coupled system.

In the model with Ekman advection, the total compensation can be partitioned between the contribution from the atmosphere $\left(\delta F_{\mathrm{A}}\right)$ and that from the Ekman flow $\left(\delta F_{\mathrm{Ek}}\right)$. The fraction of total compensation that is accomplished by the atmospheric transport is the atmospheric compensation $C_{\mathrm{A}}$ (i.e., $C_{\mathrm{A}} \equiv \delta F_{\mathrm{A}} /\left(\delta F_{\mathrm{A}}+\delta F_{\mathrm{Ek}}\right)$ ). Similarly, the Ekman compensation $C_{E k}$ is defined as $C_{E k} \equiv \delta F_{E k} /$ $\left(\delta F_{\mathrm{A}}+\delta F_{\mathrm{Ek}}\right)$. By construction, the sum of $C_{\mathrm{A}}$ and $C_{\mathrm{Ek}}$ is 1 . In the model without Ekman advection, $C_{A}=1$ and $C_{\mathrm{Ek}}=0$. For a fixed total compensation $C$, a larger $C_{\mathrm{Ek}}$ indicates that less energy is transported via the anomalous $\mathrm{HC}$, dampening the ITCZ shift. The Ekman compensation reaches up to $70 \%$ in the case with the weakest $F_{\mathrm{SO}}$ (Fig. $5 \mathrm{~d}$ ). As a result, the anomalous $\mathrm{HC}$ is $50 \%$ weaker (Fig. 4), and the energy flux equator is shifted less compared to the model without Ekman advection (Fig. 6a). The tropical precipitation response exhibits little or a slightly southward shift (Figs. $3 \mathrm{~d}$ and $6 \mathrm{~b}$ ). This is because the Ekman flow induces anomalous warming (cooling) in the southern (northern) deep tropics, leading to an anomalous rising (sinking) motion just south (north) of the equator (Figs. $4 \mathrm{~b}$ and $7 \mathrm{~b}$ ). Hence, the latitude of the maximum moisture convergence and the energy flux equator decouple. We demonstrate that an inclusion of Ekman advection completely damps or reverses the tropical rainfall response, as in the fully coupled model experiments mentioned previously. ${ }^{53-56,61,62}$ Our results suggest that ocean Ekman advection can play a critical role in the coupled climate system. 

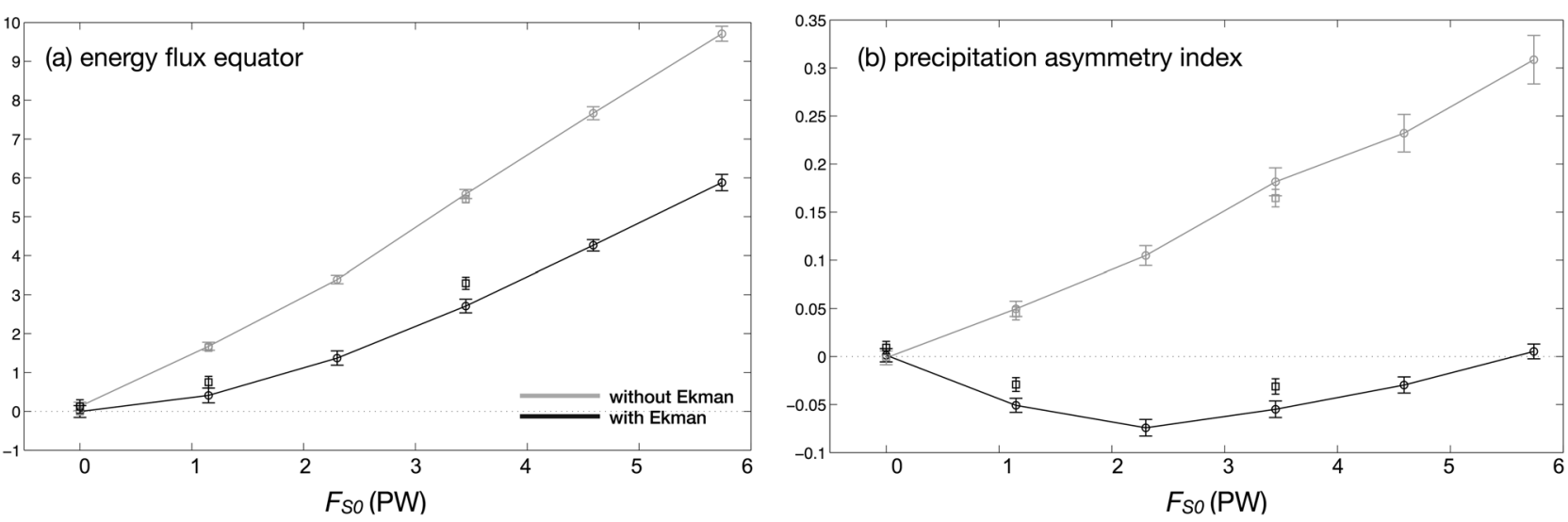

Fig. 6 Response to extratropical thermal forcing. a The position of energy flux equator and $\mathbf{b}$ averaged precipitation between equator to $20^{\circ} \mathrm{N}$ minus the average between equator and $20^{\circ} \mathrm{S}$, divided by the average between $20^{\circ} \mathrm{S}$ and $20^{\circ} \mathrm{N}$, as a function of $F_{\mathrm{So}}$. The tropical precipitation asymmetry index in (b) is zero if the profile is perfectly symmetric about the equator. The index is positive (negative) for a northward (southward) ITCZ shift. Dash-dot (solid) is for the model without (with) the Ekman advection. The squares indicate the results from the model with a mixed layer depth of $25 \mathrm{~m}$, and bars indicate the $95 \%$ confidence interval
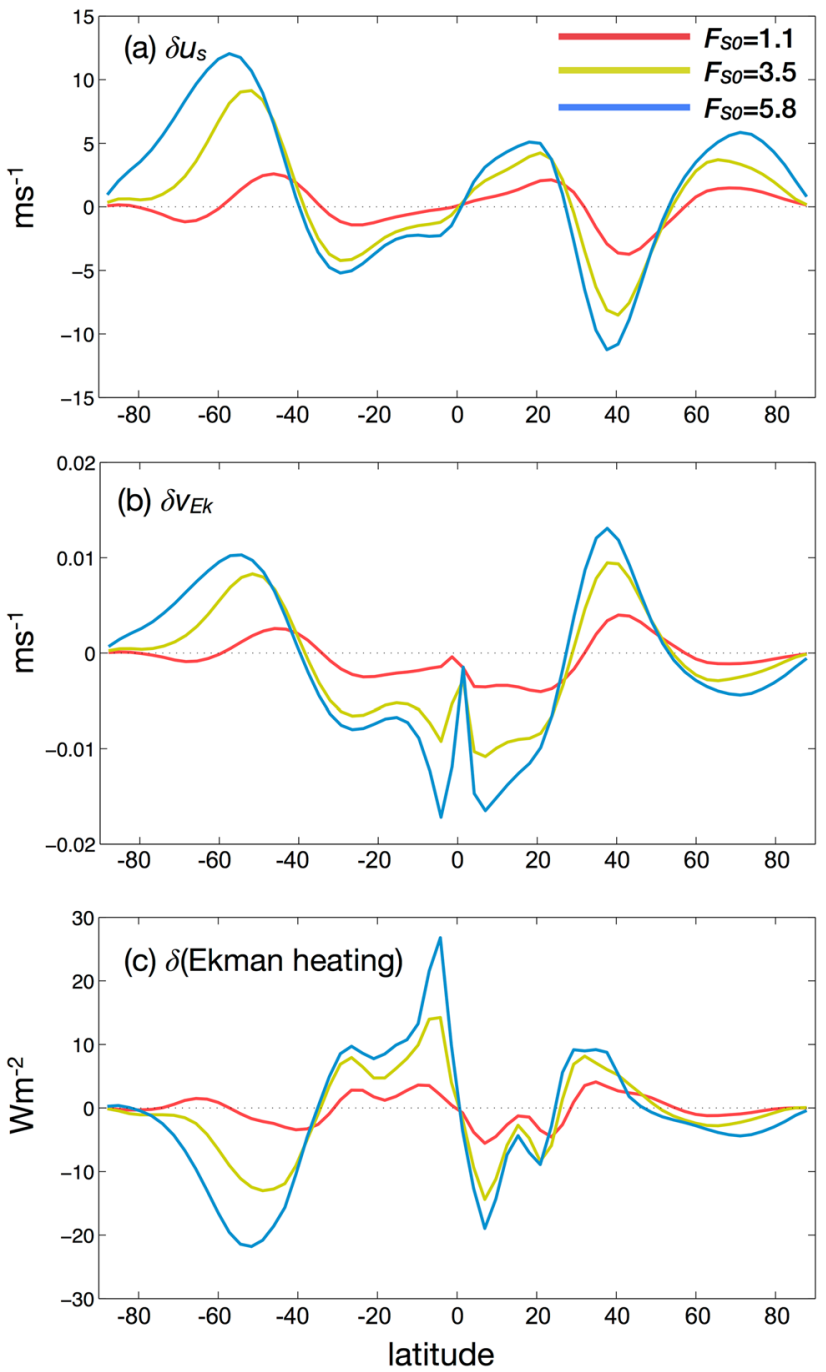

Fig. 7 Zonal-mean response of meridional Ekman flow. a The anomalous surface zonal wind $\left(\mathrm{m} \mathrm{s}^{-1}\right)$. b The anomalous meridional Ekman flow $\left(v_{\mathrm{Ek}} ; \mathrm{m} \mathrm{s}^{-1}\right)$. c The anomalous Ekman-driven heat advection $\left(\mathrm{W} \mathrm{m}^{-2}\right)$
Complications arise from the competing effects of the tropical and the extratropical components of Ekman-driven heating. As the amplitude of the forcing increases, the positive feedback from the extratropical component is intensified (Fig. 5c), leading to a reduction of Ekman compensation to $30 \%$ in the case with the strongest $F_{\mathrm{SO}}$ (Fig. $5 \mathrm{~d}$ ). The results indicate a large dependence of the Ekman advection effect on the response of extratropical jet. The response in the jet latitude is a function of its climatological value, $^{80,81}$ suggesting a sensitivity of the effect of Ekman advection to the mean state. This may partly explain a large multi-model spread of the partitioning of the energy transport adjustments between atmosphere and ocean. ${ }^{53-56,61,62}$ The partitioning is also expected to be sensitive to the location of the prescribed forcing because of large differences among ocean basins in the mean jet latitude, as well as the relative importance between the thermohaline and wind-driven circulation in transporting energy. Moreover, the climatological jet location is sensitive to the strength of transient eddy fluxes, ${ }^{82}$ which controls the communication between the extratropics and the $\mathrm{HC} .^{15}$ This postulated intimate relationship between $\delta F_{\mathrm{A}}$ and $\delta F_{\mathrm{Ek}}$ should be studied with care in order to better understand the partitioning of energy transport between the atmosphere and ocean. ${ }^{71,83,84}$

Our simple model that only includes the meridional Ekman advection partly captures the ocean dynamical effect in balancing the external forcing. Schematic that summarizes the effect of Ekman advection is demonstrated in Fig. 8. Future studies need to investigate how the deep return flow and the upwelling effect modify the result by simulating a full dynamical coupling between the Hadley cells and ocean subtropical cells. As the ITCZ migrates away from the equator in response to inter-hemispheric forcing, off-equatorial upwelling of cold waters in the cooled hemisphere intensifies in response to cross-equatorial wind. ${ }^{85}$ This opposes the negative feedback of tropical Ekman advection. The relative importance of surface Ekman heat advection and the upwelling effect will alter the magnitude of the ITCZ shift. However, if the forcing was large enough that the ITCZ shift accompanies tropical surface westerlies, upwelling will occur near the ITCZ. This increases the ocean energy uptake in the hemisphere with the ITCZ, dampening the ITCZ shift. Another complication may result from the response in subtropical regions of Ekman pumping. That is, a larger (smaller) region of Ekman pumping in the cooled (warmed) hemisphere associated with a poleward expansion (equatorward contraction) of the region of extratropical westerlies may act as a negative feedback, leading to a reduction of the ITCZ shift. 


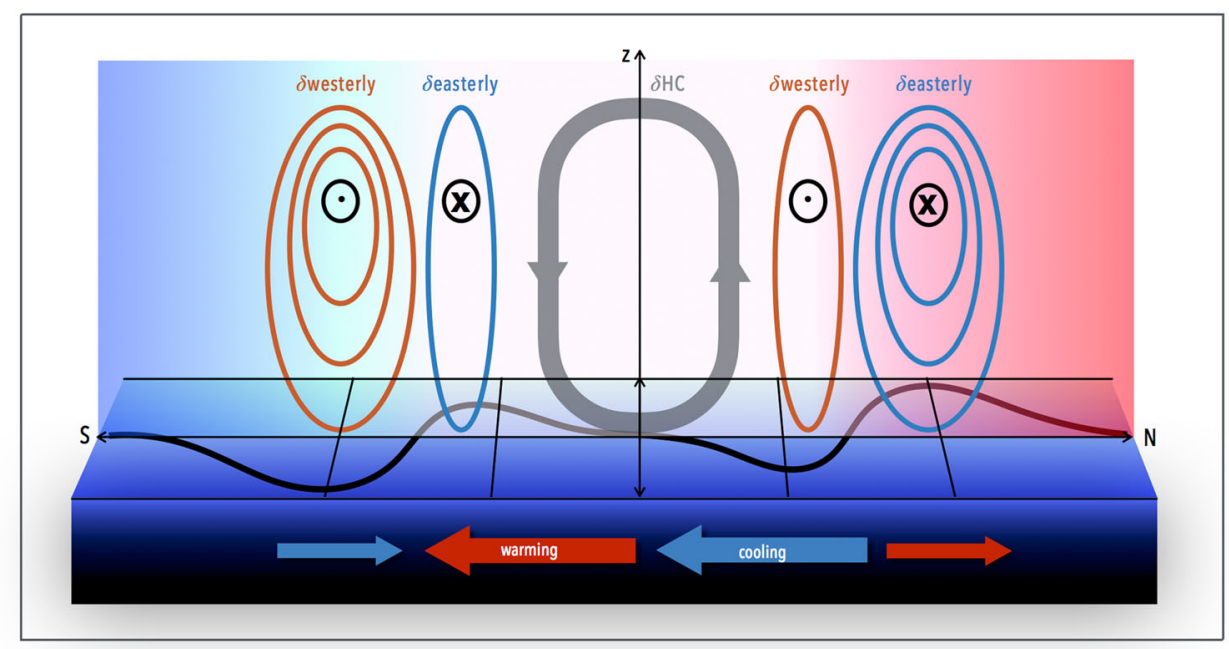

Fig. 8 Schematic that summarizes the effect of Ekman advection. Suppose the northern extratropics are warmed and the southern extratropics are cooled. With a reduction in the meridional temperature gradient in the northern extratropics, the eddy-driven jet is weakened (blue blob). The anomalous easterlies (black) induce a poleward Ekman flow that brings about warm advection (red arrow). The opposite applies to the southern extratropics. In the tropics, the anomalous Hadley cell that circulates in a counter-clockwise direction is produced to transport energy to the SH (gray). In association with a weaker northern Hadley cell, the tropical easterlies are weakened in the $\mathrm{NH}$ (black). This induces an equatorward Ekman flow that brings about cold advection (blue arrow). The opposite applies to the southern tropics. The Ekman advection in the tropics acts as a negative feedback to compensate for the prescribed forcing, whereas that in the extratropics acts as a positive feedback to amplify the prescribed forcing

\section{CONCLUDING REMARKS}

Understanding the dynamics that control tropical rainfall changes is essential for reliable future projections. The zonal-mean atmospheric energy budget has been invoked to understand changes in tropical rainfall, such as its peak location ${ }^{21}$ or width. $^{86}$ The energetics framework, in particular, provided a theory for how extratropical inter-hemispheric thermal forcing can displace tropical rainfall, as inferred by paleoclimate records. The framework, however, faces multiple challenges. For a more complete theory, an account of the following factors is necessary: (1) a theory for TGMS, which measures the efficiency with which the HC transports energy, ${ }^{16}(2)$ a prediction of cloud response based on observed relationships between cloud radiative effect and circulation, $^{44}$ (3) an expansion to include the zonal dimension to quantitatively predict the regional features, which has recently been attempted by taking into account the zonal component of divergent $\mathrm{AET}^{46}$ and (4) the effect of ocean dynamics.

Among the aforementioned limitations, we address the issue of partitioning between atmosphere and ocean energy transports. Some recent studies that incorporate fully coupled models indicate that tropical rainfall is not as sensitive to extratropical forcings ${ }^{53-56,61,62}$ as suggested by studies that disregard ocean dynamics. We propose that developing a hierarchy of ocean models is a step toward resolving the issue. The largest contributor to the meridional heat transport in the tropical ocean is the Ekman flow that is induced by surface zonal winds. Here, we have considered the meridional Ekman heat advection while neglecting the upwelling effect. (Complexity can be added by accounting for the return flow at depth by incorporating a twolayer ocean model. ${ }^{74}$ ) The Ekman advection in the tropics acts as a negative feedback that partially compensates for the prescribed anti-symmetric forcing, whereas the extratropical component acts as a positive feedback that amplifies the prescribed forcing (Fig. 8). In all of the cases under consideration, the negative tropical feedback outweighs the positive extratropical feedback. By partially balancing the prescribed forcing, the meridional Ekman advection reduces the need for AET response and damps the ITCZ shift. This is consistent with a recent study that employs the simplified atmospheric model as in our study but coupled to a full dynamical ocean model. ${ }^{65}$ The wind-driven ocean circulation is shown to strongly damp ITCZ shifts due to a robust coupling between the atmosphere's HC and ocean's subtropical cells through the trade winds. While that study focuses on the negative ocean feedback in the tropics, here we show an additional positive ocean feedback in the extratropics. It remains to be examined how the extratropical component of ocean dynamical feedback responds to the effect of a return flow in the lower layer. The strength of the positive extratropical feedback depends on the response of extratropical jet, which is a function of the mean state. ${ }^{80,81}$ Hence, the differences in the mean state across models may partly explain the multi-model spread in the degree of ocean circulation compensation. ${ }^{53-56,61,62}$ Likewise, the differences in the mean state jet latitude across basins postulates the sensitivity to the location of prescribed forcing. Therefore, a well-coordinated model intercomparison project is needed to better understand how the ocean circulation modulates the tropical response to extratropical forcing.

\section{METHODS}

The atmospheric model is a simplified moist GCM where gray radiative transfer is used in which radiative fluxes are only a function of temperature, so that water vapor and cloud radiative feedbacks are eliminated. ${ }^{67,68}$ Solar radiation is a function of latitude only that mimics the annual mean insolation. There is no seasonal or diurnal cycle in the model. It is coupled to a $50 \mathrm{~m}$ aquaplanet slab ocean with no continents or barriers. We note that the results presented herein are nearly independent of the mixed layer depth $h$. The same experiments with a shallower mixed layer depth of $25 \mathrm{~m}$ are performed whose results are compared in Figs. 5 and 6 . This insensitivity is because the heating induced by the Ekman flow is independent of $h$ due to the proportionality of $v_{\mathrm{Ek}}$ to $h$. However, the results may be modified with a temporally varying forcing or an inclusion of seasonal cycle depending on how the forcing is rectified. ${ }^{87}$

The surface zonal wind stress $\tau_{x}$ is computed via a bulk formula as $\rho_{\mathrm{a}} C_{\mathrm{D}}\left|w_{10}\right| u_{10}$, with the density of air $\rho_{\mathrm{a}}=1.2 \mathrm{~kg} \mathrm{~m}^{-3}$, a bulk transfer coefficient for momentum $C_{D}=1.3 \times 10^{-3}$, and the scalar horizontal wind speed $\left|w_{10}\right|$ and the zonal wind velocity $u_{10}$ at a height of $10 \mathrm{~m}$. 
All experiments are integrated for 20 years, with a spin-up period of 10 years.

\section{Data availability}

The data that support the findings of this study are available from the corresponding author upon request.

\section{ACKNOWLEDGEMENTS}

The authors gratefully acknowledge three anonymous reviewers whose insightful comments led to significant improvements to the manuscript. S.M.K. and Y.S. are supported by Basic Science Research Program through the National Research Foundation of Korea (NRF) funded by the Ministry of Science, ICT \& Future Planning (2016R1A1A3A04005520). S.P.X. is supported by the US National Science Foundation (1637450).

\section{AUTHOR CONTRIBUTIONS}

S.M.K. and S.P.X. designed the project. Model experiments are performed by Y.S. and data were analyzed by all authors. All authors contributed during the writing of the paper.

\section{ADDITIONAL INFORMATION}

Competing interests: The authors declare no competing financial interests.

Publisher's note: Springer Nature remains neutral with regard to jurisdictional claims in published maps and institutional affiliations.

Change history: The original version of this Article had an incorrect Article number of 2 and an incorrect Publication year of 2017. These errors have now been corrected in the PDF and HTML versions of the Article.

\section{REFERENCES}

1. Xie, S.-P. The Hadley circulation: present, past, and future, in Advances in Global Change Research, Vol. 21 (eds Diaz, H. F. \& Bradley, R. S.) 121-152 (Kluwer Academic Publishers).

2. Peterson, L. C., Haug, G. H., Hughen, K. A. \& Röhl, U. Rapid changes in the hydrologic cycle of the tropical Atlantic during the last glacial. Science 290, 1947-1951 (2000).

3. Wang, Y.-J. et al. A high-resolution absolute-dated late Pleistocene monsoon record from Hulu Cave, China. Science 294, 2345-2348 (2001).

4. Chiang, J. C. \& Bitz, C. M. Influence of high latitude ice cover on the marine Intertropical Convergence Zone. Clim. Dyn. 25, 477-496 (2005).

5. Zhang, R. \& Delworth, T. L. Simulated tropical response to a substantial weakening of the Atlantic thermohaline circulation. J. Clim. 18, 1853-1860 (2005).

6. Stouffer, R. J. et al. Investigating the causes of the response of the thermohaline circulation to past and future climate changes. J. Clim. 19, 1365-1387 (2006).

7. Swann, A. L., Fung, I. Y. \& Chiang, J. C. Mid-latitude afforestation shifts general circulation and tropical precipitation. Proc. Natl. Acad. Sci. 109, $712-716$ (2012).

8. Swann, A. L., Fung, I. Y., Liu, Y. \& Chiang, J. C. Remote vegetation feedbacks and the mid-Holocene green Sahara. J. Clim. 27, 4857-4870 (2014).

9. Kang, S. M. et al. Seasonal dependence of the effect of Arctic greening on tropical precipitation. J. Clim. 28, 6086-6095 (2015).

10. Yoshimori, M. \& Broccoli, A. J. Equilibrium response of an atmosphere-mixed layer ocean model to different radiative forcing agents: global and zonal mean response. J. Clim. 21, 4399-4423 (2008).

11. Kang, S. M., Polvani, L., Fyfe, J. \& Sigmond, M. Impact of polar ozone depletion on subtropical precipitation. Science 332, 951-954 (2011).

12. Hwang, Y.-T., Xie, S.-P., Deser, C. \& Kang, S. M. Connecting tropical climate change with Southern Ocean heat uptake, Geophys. Res. Lett., 44, 9449-9457, https://doi. org/10.1002/2017GL074972 (2017).

13. Kang, S. M., Held, I. M., Frierson, D. M. \& Zhao, M. The response of the ITCZ to extratropical thermal forcing: Idealized slab-ocean experiments with a GCM. J. Clim. 21, 3521-3532 (2008).

14. Donohoe, A., Marshall, J., Ferreira, D. \& Mcgee, D. The relationship between ITCZ location and cross-equatorial atmospheric heat transport: from the seasonal cycle to the Last Glacial Maximum. J. Clim. 26, 3597-3618 (2013)
15. Kang, S. M., Frierson, D. M. W. \& Held, I. M. The tropical response to extratropical thermal forcing in an idealized GCM: the importance of radiative feedbacks and convective parameterization. J. Atmos. Sci. 66, 2812-2827 (2009).

16. Seo, J., Kang, S. M. \& Merlis, T. M. A model intercomparison of the tropical precipitation response to a $\mathrm{CO}_{2}$ doubling in aquaplanet simulations. Geophys. Res. Lett. 44. https://doi.org/10.1002/2016GL072347 (2017).

17. Broccoli, A. J., Dahl, K. A. \& Stouffer, R. J. Response of the ITCZ to Northern Hemisphere cooling, Geophys. Res. Lett., 33, L01702, https://doi.org/10.1029/ 2005GL024546 (2006).

18. Sobel, A. H., Nilsson, J. \& Polvani, L. M. The weak temperature gradient approximation and balanced tropical moisture waves*. J. Atmos. Sci. 58, 3650-3665 (2001).

19. Donohoe, A., Marshall, J., Ferreira, D., Armour, K. \& McGee, D. The interannual variability of tropical precipitation and interhemispheric energy transport. J. Clim. 27, 3377-3392 (2014).

20. Bischoff, T. \& Schneider, T. Energetic constraints on the position of the intertropical convergence zone. J. Clim. 27, 4937-4951 (2014).

21. Schneider, T., Bischoff, T. \& Haug, G. H. Migrations and dynamics of the intertropical convergence zone. Nature 513, 45-53 (2014).

22. Seo, J., Kang, S. M. \& Frierson, D. M. Sensitivity of intertropical convergence zone movement to the latitudinal position of thermal forcing. J. Clim. 27, 3035-3042 (2014).

23. Frierson, D. M. et al. Contribution of ocean overturning circulation to tropical rainfall peak in the Northern Hemisphere. Nat. Geosci. 6, 940-944 (2013).

24. Marshall, J., Donohoe, A., Ferreira, D. \& McGee, D. The ocean's role in setting the mean position of the inter-tropical convergence zone. Clim. Dyn. 42, 1967-1979 (2014).

25. Fuckar, N. S., Xie, S.-P., Farneti, R., Maroon, E. A. \& Frierson, D. M. Influence of the extratropical ocean circulation on the intertropical convergence zone in an idealized coupled general circulation model. J. Clim. 26, 4612-4629 (2013).

26. Kang, S. M., Held, I. M. \& Xie, S.-P. Contrasting the tropical responses to zonally asymmetric extratropical and tropical thermal forcing. Clim. Dyn. 42, 2033-2043 (2014).

27. Philander, S. et al. Why the ITCZ is mostly north of the equator. J. Clim. 9, 2958-2972 (1996).

28. Fuckar, N. S., Maroon, E. A., Frierson, D. M. W. \& Farneti R. Tropical and extratropical sources of hemispheric asymmetry of the Intertropical Convergence Zone in an Idealized GCM. Dyn. Stat. Clim. Syst. (2017).

29. Takahashi, K. \& Battisti, D. S. Processes controlling the mean tropical Pacific precipitation pattern. Part I: The Andes and the eastern Pacific ITCZ. J. Clim. 20, 3434-3451 (2007).

30. Maroon, E. A., Frierson, D. M. \& Battisti, D. S. The tropical precipitation response to Andes topography and ocean heat fluxes in an aquaplanet model. J. Clim. 28 381-398 (2015).

31. Kang, S. M., Seager, R., Frierson, D. M. \& Liu, X. Croll revisited: why is the northern hemisphere warmer than the southen hemisphere? Clim. Dyn. 44, 1457-1472 (2015).

32. Dima, I. M. \& Wallace, J. M. On the seasonality of the Hadley cell. J. Atmos. Sci. $\mathbf{6 0}$, 1522-1527 (2003).

33. Frierson, D. M. \& Hwang, Y.-T. Extratropical influence on ITCZ shifts in slab ocean simulations of global warming. J. Clim. 25, 720-733 (2012).

34. Hwang, Y. T., Frierson, D. M. \& Kang, S. M. Anthropogenic sulfate aerosol and the southward shift of tropical precipitation in the late 20th century. Geophys. Res. Lett. 40, 2845-2850 (2013).

35. Zhang, X., Liu, H. \& Zhang, M. Double ITCZ in coupled ocean-atmosphere models: from CMIP3 to CMIP5. Geophys. Res. Lett. 42, 8651-8659 (2015).

36. Hwang, Y.-T. \& Frierson, D. M. Link between the double-Intertropical Convergence Zone problem and cloud biases over the Southern Ocean. Proc. Natl. Acad. Sci. 110, 4935-4940 (2013).

37. Chou, C., Wu, T.-C. \& Tan, P.-H. Changes in gross moist stability in the tropics under global warming. Clim. Dyn. 41, 2481-2496 (2013).

38. Merlis, T. M., Schneider, T., Bordoni, S. \& Eisenman, I. The tropical precipitation response to orbital precession. J. Clim. 26, 2010-2021 (2013).

39. Hill, S. A., Ming, Y. \& Held, I. M. Mechanisms of forced tropical meridional energy flux change. J. Clim. 28, 1725-1742 (2015)

40. Feldl, N. \& Bordoni, S. Characterizing the Hadley circulation response through regional climate feedbacks. J. Clim. 29, 613-622 (2016).

41. Shaw, T. A., Voigt, A., Kang, S. M. \& Seo, J. Response of the intertropical convergence zone to zonally asymmetric subtropical surface forcings. Geophys. Res. Lett. 42, 9961-9969 (2015).

42. Shin, Y., Kang, S. M. \& Watanabe, M. Dependence of Arctic climate on the latitudinal position of stationary waves and to high-latitudes surface warming. Clim. Dyn. https://doi.org/10.1007/s00382-017-3543-y (2017). 
43. Zhang, R., Kang, S. M. \& Held, I. M. Sensitivity of climate change induced by the weakening of the Atlantic meridional overturning circulation to cloud feedback. J. Clim. 23, 378-389 (2010)

44. Voigt, A., Stevens, B., Bader, J. \& Mauritsen, T. Compensation of hemispheric albedo asymmetries by shifts of the ITCZ and tropical clouds. J. Clim. 27, 1029-1045 (2014).

45. Bony, S., Dufresne, J.-L., Le Treut, H., Morcrette, J.-J. \& Senior, C. On dynamic and thermodynamic components of cloud changes. Clim. Dyn. 22, 71-86 (2004).

46. Boos, W. R. \& Korty, R. L. Regional energy budget control of the intertropical convergence zone and application to mid-Holocene rainfall. Nat. Geosci. 9, 892-897 (2016).

47. McGee, D., Donohoe, A., Marshall, J. \& Ferreira, D. Changes in ITCZ location and cross-equatorial heat transport at the Last Glacial Maximum, Heinrich Stadial 1, and the mid-Holocene. Earth Planet. Sci. Lett. 390, 69-79 (2014).

48. Bordoni, S. \& Schneider, T. Monsoons as eddy-mediated regime transitions of the tropical overturning circulation. Nat. Geosci. 1, 515-519 (2008).

49. Chou, C. \& Neelin, J. D. Mechanisms limiting the northward extent of the Northern Summer Monsoons over North America, Asia, and Africa*. J. Clim. 16, 406-425 (2003).

50. Shaw, T. A. On the role of planetary-scale waves in the abrupt seasonal transition of the Northern Hemisphere general circulation. J. Atmos. Sci. 71, 1724-1746 (2014).

51. Xie, S.-P. \& Saiki, N. Abrupt onset and slow seasonal evolution of summer monsoon in an idealized GCM simulation. J. Meteorol. Soc. Jpn. 77, 949-968 (1999).

52. Adam, O., Bischoff, T. \& Schneider, T. Seasonal and interannual variations of the energy flux equator and ITCZ. Part I: zonally averaged ITCZ position. J. Clim. 29, 3219-3230 (2016).

53. Kay, J. E. et al. Global climate impacts of fixing the Southern Ocean shortwave radiation bias in the Community Earth System Model (CESM). J. Clim. 29, 4617-4636 (2016).

54. Hawcroft, M. et al. Southern Ocean albedo, inter-hemispheric energy transports and the double ITCZ: global impacts of biases in a coupled model. Clim. Dyn. https://doi.org/10.1007/s00382-016-3205-5 (2016).

55. Xiang, B., Zhao, M., Ming, Y., Golaz, J.-C. \& Kang, S. M. Contrasting association of ITCZ position with the Southern Ocean and Southern Tropical radiative forcings in a GFDL coupled model. Geophys. Res. Lett. (2017).

56. Mechoso, C. R. et al. Can reducing the incoming energy flux over the Southern Ocean in a CGCM improve its simulation of tropical climate? Geophys. Res. Lett. 43, 11057-11063 (2016).

57. Cabré, A., Marinov, I. \& Gnanadesikan, A. Global atmospheric teleconnections and multi-decadal climate oscillations driven by Southern Ocean convection. J. Clim. https://doi.org/10.1175/JCLI-D-16-0741.1 (2017).

58. Kay, J. et al. The Community Earth System Model (CESM) large ensemble project: a community resource for studying climate change in the presence of internal climate variability. Bull. Am. Meteorol. Soc. 96, 1333-1349 (2015).

59. Collins, W. et al. Development and evaluation of an Earth-system model-HadGEM2. Geosci. Model Dev. 4, 1051-1075 (2011).

60. Gent, P. R. et al. The community climate system model version 4. J. Clim. 24, 4973-4991 (2011).

61. Deser, C., Tomas, R. A. \& Sun, L. The role of ocean-atmosphere coupling in the zonal-mean atmospheric response to Arctic sea ice loss. J. Clim. 28, 2168-2186 (2015).

62. Tomas, R. A., Deser, C. \& Sun, L. The role of ocean heat transport in the global climate response to projected arctic sea ice loss. J. Clim. 29, 6841-6859 (2016).

63. Vecchi, G. A. et al. On the seasonal forecasting of regional tropical cyclone activity. J. Clim. 27, 7994-8016 (2014).

64. Galbraith, E. D. et al. climate variability and radiocarbon in the CM2Mc earth system model. J. Clim. 24, 4230-4254 (2011).

65. Green, B. \& Marshall, J. Coupling of trade winds with ocean circulation damps ITCZ shifts. J. Clim. https://doi.org/10.1175/JCLI-D-16-0818.1 (2017).

66. Held, I. M. The gap between simulation and understanding in climate modeling. Bull. Am. Meteorol. Soc. 86, 1609-1614 (2005).

67. Frierson, D. M., Held, I. M. \& Zurita-Gotor, P. A gray-radiation aquaplanet moist GCM. Part I: static stability and eddy scale. J. Atmos. Sci. 63, 2548-2566 (2006).
68. Frierson, D. M. The dynamics of idealized convection schemes and their effect on the zonally averaged tropical circulation. J. Atmos. Sci. 64, 1959-1976 (2007).

69. Levitus, S. Meridional Ekman heat fluxes for the world ocean and individual ocean basins. J. Phys. Oceanogr. 17, 1484-1492 (1987).

70. Klinger, B. A. \& Marotzke, J. Meridional heat transport by the subtropical cell. J. Phys. Oceanogr. 30, 696-705 (2000).

71. Held, I. M. The partitioning of the poleward energy transport between the tropical ocean and atmosphere. J. Atmos. Sci. 58, 943-948 (2001).

72. Schott, F. A., McCreary, J. P. \& Johnson, G. C. Shallow overturning circulations of the tropical-subtropical oceans, in Earth Climate: The Ocean-Atmosphere Interaction (eds Wang, C. Xie, S.-P. \& Carton, J. A.) vol. 147, 261-304 (AGU, Washington DC, 2004).

73. Xie, S.-P. A dynamic ocean-atmosphere model of the tropical Atlantic decadal variability. J. Clim. 12, 64-70 (1999).

74. Codron, F. Ekman heat transport for slab oceans. Clim. Dyn. 38, 379-389 (2012).

75. Peng, S., Robinson, W. A., Li, S. \& Alexander, M. A. Effects of Ekman transport on the NAO response to a tropical Atlantic SST anomaly. J. Clim. 19, 4803-4818 (2006).

76. Alexander, M. A. \& Scott, J. D. The role of Ekman ocean heat transport in the Northern Hemisphere response to ENSO. J. Clim. 21, 5688-5707 (2008).

77. Ceppi, P., Hwang, Y. T., Liu, X., Frierson, D. M. \& Hartmann, D. L. The relationship between the ITCZ and the southern hemispheric eddy-driven jet. J. Geophys. Res. Atmos. 118, 5136-5146 (2013).

78. Walker, C. C. \& Schneider, T. Eddy influences on Hadley circulations: simulations with an idealized GCM. J. Atmos. Sci. 63, 3333-3350 (2006).

79. Lindzen, R. S. \& Hou, A. V. Hadley circulations for zonally averaged heating centered off the equator. J. Atmos. Sci. 45, 2416-2427 (1988).

80. Kidston, J. \& Gerber, E. Intermodel variability of the poleward shift of the austral jet stream in the CMIP3 integrations linked to biases in 20th century climatology. Geophys. Res. Lett. 37, L09708, https://doi.org/10.1029/2010GL042873 (2010).

81. Barnes, E. A. \& Polvani, L. Response of the midlatitude jets, and of their variability, to increased greenhouse gases in the CMIP5 models. J. Clim. 26, 7117-7135 (2013).

82. Kang, I.-S., Kug, J.-S., Lim, M.-J. \& Choi, D.-H. Impact of transient eddies on extratropical seasonal-mean predictability in DEMETER models. Clim. Dyn. 37, 509-519 (2011).

83. Czaja, A. \& Marshall, J. The partitioning of poleward heat transport between the atmosphere and ocean. J. Atmos. Sci. 63, 1498-1511 (2006).

84. Vallis, G.K. \& Farneti, R. Meridional energy transport in the coupled atmosphereocean system: scaling and numerical experiments. Q. J. R. Meteorol. Soc. 135, 1643-1660 (2009).

85. Chang, P. \& Philander, S. G. A coupled ocean-atmosphere instability of relevance to the seasonal cycle. J. Atmos. Sci. 51, 3627-3648 (1994).

86. Byrne, M. P. \& Schneider, T. Narrowing of the ITCZ in a warming climate: Physical mechanisms. Geophys. Res. Lett. 43, 11350-11357 https://doi.org/10.1002/ 2016GL070396 (2016)

87. Donohoe, A., Frierson, D. M. \& Battisti, D. S. The effect of ocean mixed layer depth on climate in slab ocean aquaplanet experiments. Clim. Dyn. 43, 1041-1055 (2014).

Open Access This article is licensed under a Creative Commons Attribution 4.0 International License, which permits use, sharing, adaptation, distribution and reproduction in any medium or format, as long as you give appropriate credit to the original author(s) and the source, provide a link to the Creative Commons license, and indicate if changes were made. The images or other third party material in this article are included in the article's Creative Commons license, unless indicated otherwise in a credit line to the material. If material is not included in the article's Creative Commons license and your intended use is not permitted by statutory regulation or exceeds the permitted use, you will need to obtain permission directly from the copyright holder. To view a copy of this license, visit http://creativecommons. org/licenses/by/4.0/.

(c) The Author(s) 2018 